\title{
Analisis Strategi Pembiayaan Usaha Mikro dan Kecil Melalui Dana Bergulir pada Lembaga Pengelola Dana Bergulir
}

\author{
Analysis of Micro and Small Business Financing Strategies through Revolving Funds at Revolving \\ Fund Management Institutions
}

\author{
Adi Trisnojuwono ${ }^{1 *}$, Aida Vitayala S. Hubeis ${ }^{2 *}$, dan Eko Ruddy Cahyadi ${ }^{3 *}$ \\ ${ }^{1}$ Lembaga Pengelola Dana Bergulir Koperasi dan Usaha Mikro, Kecil dan Menengah (LPDB-KUMKM) \\ ${ }^{2}$ Departemen Komunikasi dan Pengembangan Masyarakat Fakultas Ekologi Manusia, IPB \\ ${ }^{3}$ Departemen Manajemen Fakultas Ekonomi dan Manajemen, IPB \\ "Jl. Kamper Kampus IPB Dramaga Bogor 16680
}

\begin{abstract}
ABSTRAK
Kementerian Koperasi dan UKM mendirikan Lembaga Pengelola Dana Bergulir Koperasi, Usaha Mikro, Kecil dan Menengah (LPDB-KUMKM), dalam rangka mewujudkan amanat undang-undang nomor 20 tahun 2008, yang bertujuan mengelola dan mengembangkan dana bergulir KUMKM secara profesional dan akuntabel. Meningkatnya jumlah layanan penyaluran dana bergulir oleh LPDB-KUMKM dan terjadinya penurunan tingkat klasifikasi pinjaman dalam kategori lancar mendorong perlunya melakukan evaluasi penyaluran pinjaman atau pembiayaan melalui (1) analisis faktor-faktor yang memengaruhi kinerja dana bergulir LPDB-KUMKM dan (2) merumuskan strategi efektif untuk meningkatkan kinerja dana bergulir LPDB-KUMKM. Metode dalam penelitian ini meliputi analisis deskriptif, analisis regresi logistik dan AHP. Hasil analisis menunjukkan faktor-faktor nyata memengaruhi kinerja dana bergulir adalah pola pinjaman atau pembiayaan (pola konvensional atau syariah), plafon pinjaman dan lama berdirinya usaha. Usulan strategi yang dapat dipertimbangkan dalam meningkatkan kinerja LPDB-KUMKM dengan memerhitungkan peningkatan efektivitas penyaluran pinjaman atau pembiayaan, yang meliputi saluran pinjaman atau pembiayaan dan faktor-faktor yang berpengaruh nyata terhadap sukses pengembalian.
\end{abstract}

Kata kunci: analisis strategi, dana bergulir, LPDB, pembiayaan usaha, usaha mikro dan kecil

\begin{abstract}
The Ministry of Cooperatives and SMEs established a Revolving Fund Management Institution for the Micro, Small and Medium Enterprises (LPDB-KUMKM) in order to realize the mandate of Law No. 20 of 2008, with the aim of managing and developing revolving funds for the Micro, Small and Medium Enterprises professionally and accountably. The increasing number of Revolving Fund distribution services and the decreasing level of loan classification in the current category encouraged the need to evaluate loan or financing distribution through (1) analysis of factors affecting LPDB-KUMKM revolving fund performance and (2) to formulate effective strategies to improve the performance of revolving fund for the Micro, Small and Medium Enterprises. The method used in this research are, descriptive analysis, logistic regression analysis and AHP. The analysis result shows the significant factors that influence the performance of the revolving fund efficiency are financing schemes (conventional or syariah schemes), loan plafond and business establishment period. The proposed strategies that can be considered in improving LPDB-KUMKM's performance take into account the increasing effectiveness of loan or financing disbursement, which includes loan or financing channels and factors that significantly influence the success of return.
\end{abstract}

Key words: business financing, LPDB, micro and small business, revolving fund, strategy analysis

\footnotetext{
*) Korespondensi:

Jl. MT Haryono Kav. 52-53 Jakarta Selatan, email: aditrisnojuwono@gmail.com
} 


\section{PENDAHULUAN}

Usaha Kecil dan Menengah (UKM) sebagai salah satu komponen dalam industri nasional, mempunyai peranan sangat penting dalam perekonomian nasional, penyerapan tenaga kerja, pemerataan distribusi hasil-hasil pembangunan, dan penanggulangan kemiskinan (Munizu, 2013). Peran strategik UMKM dalam perekonomian Indonesia ditunjukkan oleh besarnya kontribusi UMKM dalam pembentukan Product Domestic Brutto (PDB), penyerapan tenaga kerja dan pembentukan total ekspor secara nasional. Jumlah pelaku UMKM tercatat 57,8 juta unit usaha, atau 99,99\% dari total pelaku usaha di Indonesia yang tercatat sebanyak 57,9 juta unit usaha pada tahun 2013. Kontribusi UMKM dalam pembentukan total PDB nasional (atas dasar harga berlaku) tercatat 5.440 triliun rupiah atau $60,34 \%$ dari total $P D B$ nasional, penyerapan tenaga kerja sebanyak 114,14 juta atau $96,99 \%$ dari total tenaga kerja yang bekerja dan pembentukan total ekspor 182 triliun rupiah atau $15,68 \%$ dari total ekspor nasional (Kementerian Koperasi dan UKM 2014).

Pendekatan pembangunan yang ditujukan pada pelaku ekonomi, khususnya pada Koperasi dan Usaha Mikro, Kecil, Menengah (UMKM), dipandang amat penting. Langkah ini sekaligus mempertegas penataan struktur pelaku ekonomi nasional yang selama ini dalam kondisi dualistik dan timpang. Pembangunan yang ditujukan kepada Koperasi dan UMKM diharapkan menghantarkan penataan struktur pelaku ekonomi nasional lebih padu dan seimbang, baik dalam skala usaha, strata dan sektoral, sehingga berkembang struktur pelaku ekonomi nasional yang kokoh dan mandiri (Kementerian Koperasi dan UKM, 2011).

Kementerian Koperasi dan UKM mendirikan Lembaga Pengelola Dana Bergulir Koperasi, Usaha Mikro, Kecil dan Menengah (LPDBKUMKM) dalam rangka mewujudkan amanat undang-undang nomor 20 tahun 2008, yang bertujuan mengelola dan mengembangkan dana bergulir KUMKM secara profesional dan akuntabel, guna mendukung upaya peningkatan akses pembiayaan usaha KUMKM di Indonesia. Mengacu pada visi dan misi LPDB-KUMKM, tolok ukur keberhasilan LPDB-KUMKM adalah: (1) sukses dalam penyaluran dana secara transparan dan akuntabel; (2) sukses dalam pengembalian yang diukur dengan tingkat kolektibilitas yang terkendali sesuai dengan yang ditetapkan; (3) sukses pemanfaatan oleh Koperasi dan UMKM; dan (4) sukses peningkatan usaha koperasi dan UMKM (Tamba et al., 2013).

Pemberian pinjaman atau pembiayaan kepada pelaku koperasi dan UMKM, baik secara langsung maupun melalui perantara, merupakan wujud dari pelaksanaan fungsi dan peran LPDBKUMKM sebagai instrumen kebijakan pemerintah di bidang pembiayaan kepada koperasi dan UMKM, meningkatkan akses pembiayaan bagi koperasi dan UMKM, agar dapat meningkatkan usaha dan daya saing produk yang akan dihasilkan. Data realisasi penyaluran dana bergulir LPDB-KUMKM periode 2008 hingga akhir tahun 2015, menunjukkan adanya jumlah layanan kepada UMKM yang meningkat dari tahun ke tahun, yaitu dari 3.820 UMKM pada tahun 2008 menjadi 186.733 UMKM pada tahun 2015 (LPDB-KUMKM, 2015). Meningkatnya jumlah layanan penyaluran dana bergulir oleh LPDB-KUMKM dan terjadinya penurunan tingkat klasifikasi pinjaman dalam kategori lancar, maka perlu dilakukan evaluasi terhadap kinerja dan strategi penyaluran pinjaman yang selama ini dilaksanakan oleh LPDB-KUMKM.

Penelitian ini bertujuan menganalisis faktor-faktor yang memengaruhi kinerja dana bergulir dan merumuskan strategi efektif untuk meningkatkan kinerja dana bergulir LPDBKUMKM.

\section{METODE PENELITIAN}

Penelitian ini dilakukan dengan metode analisis deskriptif, analisis regresi logistik dan Analytic Hierarchy Process (AHP). Analisis deskriptif dilakukan untuk mengetahui profil atau gambaran umum kondisi penyaluran pinjaman atau pembiayaan oleh LPDB-KUMKM. Analisis regresi logistik dilakukan untuk mengetahui faktor-faktor yang memengaruhi kinerja dana bergulir LPDB-KUMKM. AHP dilakukan untuk memberikan gambaran berdasarkan wawasan dan pengalaman pengelola dana bergulir yang terkait saluran pinjaman atau pembiayaan efektif dalam penyaluran pinjaman. Hasil analisis akan digunakan sebagai dasar dalam merumuskan strategi pembiayaan dana bergulir oleh LPDBKUMKM. 


\section{HASIL DAN PEMBAHASAN}

\section{Analisis Deskriptif}

Data dalam penelitian ini menggunakan data primer yang dimiliki oleh LPDB-KUMKM. Data penelitian menggunakan data mitra penerima pinjaman dana bergulir dari LPDBKUMKM tahun 2012-2016 (data 5 tahun terakhir). Jumlah mitra penerima pinjaman LPDB-KUMKM dari tahun 2012-2016 sebanyak 2.500 mitra. Jumlah contoh yang diambil sebanyak 345 sampel. Ukuran contoh minimum ditentukan dengan menggunakan metode Slovin dengan persen kelonggaran 5\%. Komposisi jumlah dan jenis mitra contoh disajikan dalam Tabel 1.

Tabel 1. Jumlah dan jenis contoh mitra

\begin{tabular}{lc}
\hline \multicolumn{1}{c}{ Jenis Mitra } & $\begin{array}{c}\text { Jumlah contoh } \\
\text { (mitra) }\end{array}$ \\
\hline Koperasi & 201 \\
LKB & 34 \\
LKBB & 3 \\
UKM & 107 \\
Total & 345 \\
\hline
\end{tabular}

Data contoh menunjukkan mitra yang masuk dalam klasifikasi lancar 274 mitra $(79,4 \%)$ dari total contoh. Jumlah mitra yang masuk dalam klasifikasi tidak lancar 71 mitra (20,6\%). Data juga menunjukkan bahwa jenis mitra yang masuk dalam klasifikasi pinjaman tidak lancar adalah koperasi dan UKM, sedangkan LKB dan LKBB seluruhnya masuk dalam klasifikasi pinjaman lancar.

Lama usaha adalah umur usaha mitra LPDB-KUMKM yang diukur dalam satuan bulan. Lama usaha beroperasi berhubungan dengan kurva pembelajaran, dimana pemain lama kemungkinan besar telah banyak belajar dari pengalaman yang dibandingkan dengan pemain baru. Kristiansen, Furuholt, dan Wahid (2003) menemukan bahwa lama usaha beroperasi memiliki hubungan nyata terhadap kesuksesan bisnis. Data contoh menunjukkan 82 mitra $(23,8 \%)$ memiliki lama usaha 60-120 bulan, 105 mitra (30,4\%) memiliki lama usaha kurang dari 60 bulan dan 158 mitra $(45,8 \%)$ memiliki lama usaha lebih dari 120 bulan.

\section{Analisis Regresi Logistik}

Analisis regresi logistik dilakukan untuk menganalisis faktor-faktor yang memengaruhi kinerja dana bergulir LPDB-KUMKM. Permodelan logit menggunakan seluruh jumlah contoh, yaitu 345 mitra LPDB-KUMKM hasil pemilihan secara acak.

Pengujian parameter secara simultan dengan uji $G$ menunjukkan nilai khi kuadrat 63,791 dengan taraf nyata $0,000(<0,05)$ sehingga menolak $\mathrm{H}_{0}$. Hal ini menunjukkan penambahan peubah independen dapat memberikan pengaruh nyata terhadap model atau model dinyatakan fit. Klasifikasi model regresi logistik juga menunjukkan tingkat keakuratan model yang dihasilkan $81,2 \%$. Nilai Nagelkerke R Square 0,265 menunjukkan kemampuan peubah independen dalam menjelaskan peubah dependen $26,5 \%$, dan sisanya (73,5\%) dipengaruhi oleh faktor lain di luar model. Hasil uji model regresi logistik biner ditunjukkan dalam Tabel 2.

Peubah dengan nilai koefisien positif adalah jangka waktu, tarif layanan, plafon pinjaman dan lama usaha, sehingga dapat diartikan bahwa peningkatan pada peubah tersebut akan mendorong kelancaran tingkat pengembalian pinjaman atau pembiayaan. Peubah dengan nilai koefisien negatif adalah pola pembiayaan dan ketersediaan agunan, sehingga dapat diartikan peningkatan pada peubah tersebut akan menghambat kelancaran tingkat pengembalian pinjaman atau pembiayaan.

Tabel 2. Hasil uji model regresi logistik biner

\begin{tabular}{lrrr}
\hline \multicolumn{1}{c}{ Variabel } & \multicolumn{1}{c}{ B } & \multicolumn{1}{c}{ Sig. } & Exp $(\mathrm{B})$ atau Odds Ratio \\
\hline Jangka Waktu $\left(\mathrm{X}_{1}\right)$ & 0,008 & 0,590 & 1,008 \\
Tarif Layanan $\left(\mathrm{X}_{2}\right)$ & 0,132 & $0,092^{*}$ & 1,141 \\
Pola Pembiayaan $\left(\mathrm{X}_{3}\right)$ & $-1,120$ & $0,011^{* *}$ & 0,326 \\
Plafon Pinjaman $\left(\mathrm{X}_{4}\right)$ & 0,000 & $0,001^{* *}$ & 1,000 \\
Lama Usaha $\left(\mathrm{X}_{5}\right)$ & 0,004 & $0,006^{* *}$ & 1,004 \\
Ketersediaan Agunan $\left(\mathrm{X}_{6}\right)$ & $-38,911$ & 0,997 & 0,000 \\
Saluran Koperasi $\left(\mathrm{D}_{1}\right)$ & $-2,456$ & $0,000^{* *}$ & 0,086 \\
Saluran LKB $\left(\mathrm{D}_{2}\right)$ & 20,498 & 0,997 & 0,000 \\
Saluran LKBB $\left(\mathrm{D}_{3}\right)$ & $-20,383$ & 0,999 & 8565373871100000000,000 \\
Constant & 41,291 & 0,997 &
\end{tabular}


Pendugaan odds ratio memiliki batas kepercayaan $5 \%$, nilai ini menunjukkan besar kemungkinan masing-masing peubah independen dalam memengaruhi tingkat kesuksesan pengembalian. Peubah independen nyata di dalam model pada taraf $\alpha 5 \%$ adalah peubah pola pembiayaan $\left(X_{3}\right)$, plafon pinjaman $\left(X_{4}\right)$, lama usaha $\left(X_{5}\right)$ dan saluran pemberian pinjaman melalui koperasi dibandingkan dengan UKM $\left(\mathrm{D}_{1}\right)$. Apabila taraf $\alpha$ diubah menjadi $10 \%$, maka peubah tarif layanan $\left(\mathrm{X}_{2}\right)$ juga menunjukkan nilai nyata dalam model.

Peubah jangka waktu pengembalian pinjaman dalam penelitian ini memiliki pengaruh positif, namun tidak nyata di dalam model, ditunjukkan dengan nilai $p$ value (sig) 0,590 atau > 0,05 . Hal ini sedikit berbeda dengan penelitian Lubis dan Rachmina (2011) yang menunjukkan jangka waktu pengembalian merupakan salah satu faktor berpengaruh nyata dalam tingkat pengembalian Kredit Usaha Rakyat (KUR), dimana debitur memiliki jangka waktu pengembalian lebih lama cenderung lebih lancer di dalam pengembalian kreditnya.

Peubah tarif layanan memiliki pengaruh nyata dan positif pada taraf $\alpha 10 \%$, sedangkan pada taraf $\alpha 5 \%$ tidak nyata. Peubah tarif layanan pada taraf $\alpha 10 \%$ menunjukkan peningkatan tarif layanan sebesar satu satuan akan menyebabkan kecenderungan sukses pengembalian naik 1,141 kali. Namun demikian batas atas tarif layanan yang ideal masih perlu diketahui untuk menghindari anomali gagal bayar,dimana dengan semakin tingginya tarif yang melampaui batas ideal, maka diduga berpotensi menimbulkan risiko gagal bayar meningkat, sebagaimana hasil penelitian Ladue et al. (1984) yang menunjukkan bahwa ketika tarif layanan dinaikkan diatas batas normal $(17 \%)$, maka akan berpengaruh pada kemampuan pembayaran kredit, dengan rataan kelambatan dalam pembayaran lima bulan, karena kenaikan tarif memengaruhi tingkat laba dan cashflow yang ada.

Peubah pola pembiayaan memiliki pengaruh nyata dannegatif, yang dapat diartikan bahwa pola pembiayaan syariah (kode 0 peubah independen) memiliki kecenderungan mengalami sukses pengembalian 0,326 kali dibandingkan dengan pola pinjaman konvensional (kode 1 peubah independen). Hal ini diduga karena penerapan pola pembiayaan syariah di LPDBKUMKM menganut sistem kepercayaan langsung kepada mitra, sehingga besaran kewajiban bagi hasil yang dibebankan kepada mitra per jatuh tempo pembayaran kewajiban, sepenuhnya tergantung pada kejujuran mitra dalam melakukan pembayaran. Manakala mitra tidak melakukan pembayaran kewajibannya sampai dengan maksimum tanggal tujuh bulan berikutnya setelah jatuh tempo, maka mitra tersebut dianggap mengalami kerugian atau tidak memperoleh keuntungan pada periode jatuh tempo tersebut. Dengan demikian mitra tidak dibebankan kewajiban pembayaran bagi hasil untuk periode tersebut. Namun demikian apabila pembayaran bagi hasil dilakukan oleh mitra setelah tanggal tujuh bulan berikutnya setelah jatuh tempo, maka mitra akan dikenai denda sesuai dengan kesepakatan pada akad perjanjian pembiayaan. Penelitian yang dilakukan oleh Elsiefy (2013) juga menunjukkan bahwa pola syariah cenderung lebih baik dibandingkan dengan pola konvensional, dimana bank syariah hampir tidak terdampak oleh krisis finansial tahun 2008, sebaliknya bank konvensional mengalami penurunan dibanyak sektor, salah satunya pada data NPL. NPL sebelum, ketika, dan setelah krisis pada sistem syariah cenderung stabil dan baik, sedangkan bank konvensional mengalami peningkatan terutama dibidang pembiayaan real estate dan pembiayaan perusahaan.

Peubah plafon pinjaman memiliki pengaruh nyata dan positif, yang dapat diartikan bahwa semakin tinggi plafon pinjaman, maka kecenderungan sukses dalam pengembalian semakin meningkat, namun demikian berapa batas nilai plafon pinjaman yang termasuk kategori tinggi dapat dikategorikan lancar dalam pengembalian pinjaman atau pembiayaan perlu dilakukan penelitian lebih lanjut. Sebaran data contoh yang dikategorikan berdasarkan plafon pinjaman kurang dari atau sama dengan Rp500 juta rupiah dan lebih dari Rp500 juta rupiah menunjukkan $46,1 \%$ contoh yang menerima pinjaman atau pembiayaan kurang dari atau sama dengan Rp500 juta rupiah dan $53,9 \%$ contoh yang menerima pinjaman atau pembiayaan lebih dari Rp500 juta rupiah.

Kategori penerima pinjaman atau pembiayaan kurang dari atau sama dengan Rp500 juta rupiah adalah 67 koperasi dengan jumlah pinjaman lancar 19 koperasi dan pinjaman tidak lancar 48 koperasi. UKM 92 unit dengan jumlah lancar 89 unit dan tidak lancar tiga unit UKM. Kategori penerima pinjaman atau pembiayaan lebih dari Rp500 juta rupiah adalah 134 koperasi, jumlah koperasi lancar 94 koperasi dan koperasi 
tidak lancar 40 koperasi, selanjutnya penyaluran kepada 34 LKB yang seluruhnya masuk kategori lancar, 15 UKM dengan 8 UKM lancar dan 7 UKM tidak lancar, serta penyaluran kepada 3 LKBB dengan kategori keseluruhan lancar.

Hal ini sesuai dengan hasil penelitian yang dilakukan oleh Ismanto dan Diman (2014) yang menyebutkan dalam penelitiannya bahwa omzet usaha, lama usaha dan nilai plafon pinjaman adalah faktor-faktor yang berpengaruh positif terhadap tingkat pengembalian pinjaman (lancar atau menunggak), namun berbeda dengan hasil penelitian yang dilakukan oleh Asmara (2007) yang menunjukkan bahwa jumlah pinjaman memiliki pengaruh nyata terhadap besarnya tunggakan, dimana dalam model yang digunakan tingkat pengembalian diproksi dari peubah nilai tunggakan.

Peubah lama usaha memiliki pengaruh nyata dan positif, yaitu setiap kenaikan satu satuan pada peubah lama usaha akan menyebabkan kecenderungan sukses pengembalian meningkat sebesar 1,004 kali. Sebaran data contoh berdasarkan lama usaha dan plafon pinjaman dikategorikan dalam lama usaha kurang dari atau sama dengan 60 bulan dan lebih dari 60 bulan, yang mana kategori lama usaha dibagi lagi ke dalam besaran plafon pinjaman masing-masing kurang dari atau sama dengan Rp500 juta dan lebih dari Rp500 juta. Secara umum data menunjukkan semakin tinggi lama usaha dan semakin besar plafon pinjaman, maka semakin tinggi tingkat persentase pinjaman atau pembiayaan yang berada dalam kategori lancar, yaitu $38,6 \%$ dari total contoh, sedangkan persentase pinjaman atau pembiayaan dengan plafon pinjaman atau pembiayaan yang lebih rendah tingkat pengembalian dalam kategori lancar hanya $1,7 \%$. Di sisi lain, pinjaman atau pembiayaan dengan kategori tidak lancar untuk plafon yang tinggi tercatat $12,5 \%$ dan untuk plafon yang lebih rendah tercatat $1,2 \%$. Hal ini sejalan dengan yang dikemukakan oleh Kristiansen, et al. (2003) bahwa lama usaha beroperasi memiliki hubungan nyata terhadap kesuksesan bisnis. Penelitian yang dilakukan oleh Ismanto dan Diman (2014) juga menunjukkan lama usaha adalah salah satu faktor yang berpengaruh nyata dan positif terhadap tingkat pengembalian pinjaman dalam penelitiannya yang terkait dengan efektivitas pemberian pinjaman kepada UMKM oleh koperasi.
Peubah ketersediaan agunan dalam penelitian ini memiliki pengaruh negatif, namun tidak nyata di dalam model, ditunjukkan $p$ value (sig) 0,997atau > 0,05. Hal ini berbeda dengan penelitian Boot et al. (1987) yang menunjukkan jumlah dari jaminan berpengaruh linear dengan faktor kegagalan bayar kredit, dimana semakin tinggi jumlah jaminan, maka kegagalan bayar semakin menurun, disisi lain, terjadi perubahan kelas kredit, dari yang sebelumnya tidak lancar, menjadi lancar.

Peubah saluran pembiayaan menunjukkan bahwa pembiayaan melalui koperasi memiliki pengaruh nyata dan negatif, yang dapat diartikan bahwa pemberian pinjaman kepada UKM memiliki kecenderungan sukses dalam pengembalian 0,086 kali lebih tinggi dibandingkan dengan pemberian pinjaman melalui koperasi.

\section{Analisis AHP}

Analisis AHP dilakukan melalui pengolahan horizontal dan vertikal dengan tujuan menentukan alternatif prioritas saluran yang mendukung strategi pembiayaan LPDB-KUMKM yang efektif. Analisis AHP disyaratkan memiliki batas rasio konsistensi (consistency ratio) tidak lebih dari $10 \%$.

\section{Pengolahan Horizontal}

Hasil pengolahan horizontal antar unsur sub-kriteria terhadap alternatif saluran penyaluran pinjaman atau pembiayaan LPDB-KUMKM ditunjukkan pada Tabel 3. Perbandingan alternatif saluran pembiayaan terhadap kriteria tolok ukur sukses LPDB-KUMKM menunjukkan dengan mempertimbangkan kriteria sukses pemanfaatan, maka prioritas saluran pemberian pinjaman yang dipilih adalah koperasi dan UKM. Kriteria sukses dengan bobot urutan prioritas kedua, dimana prioritas saluran pemberian pinjaman yang dipilih dengan mempertimbangkan sukses peningkatan usaha adalah UKM. Sukses pengembalian dengan bobot kriteria sukses urutan ketiga dengan ukuran utama kepatuhan pengembalian pokok, menempatkan LKB dan LKBB sebagai saluran prioritas pertama dan kedua, kemudian UKM dan koperasi sebagai prioritas ketiga dan keempat. Berikutnya sukses penyaluran sebagai kriteria sukses urutan keempat menempatkan saluran pemberian pinjaman melalui LKB sebagai pilihan saluran yang utama. 
Tabel 3. Bobot pengolahan horizontal unsur saluran pada tingkat kelima

\begin{tabular}{|c|c|c|c|c|c|}
\hline \multirow{2}{*}{ No } & \multirow{2}{*}{ Sub-Kriteria } & \multicolumn{4}{|c|}{ Saluran } \\
\hline & & Koperasi & UKM & LKB & LKBB \\
\hline 1 & Momentum waktu penyaluran & 0,280 & 0,229 & 0,294 & 0,197 \\
\hline 2 & Teknik penyaluran & 0,306 & 0,165 & 0,331 & 0,197 \\
\hline 3 & Jangka waktu & 0,360 & 0,253 & 0,195 & 0,192 \\
\hline 4 & Tingkat balas jasa & 0,345 & 0,232 & 0,218 & 0,205 \\
\hline 5 & Kepatuhan pengembalian pokok & 0,195 & 0,244 & 0,299 & 0,263 \\
\hline 6 & Kepatuhan pembayaran bunga/basil & 0,231 & 0,243 & 0,261 & 0,265 \\
\hline 7 & Skim pinjaman atau pembiayaan & 0,343 & 0,222 & 0,219 & 0,216 \\
\hline 8 & Jumlah pinjaman & 0,298 & 0,252 & 0,225 & 0,225 \\
\hline 9 & Lama berdirinya usaha & 0,361 & 0,349 & 0,124 & 0,166 \\
\hline 10 & Ketersediaan agunan & 0,400 & 0,342 & 0,098 & 0,160 \\
\hline 11 & Pertumbuhan omset & 0,368 & 0,377 & 0,107 & 0,147 \\
\hline 12 & Penyerapan tenaga kerja & 0,299 & 0,386 & 0,123 & 0,192 \\
\hline 13 & Kesesuaian peruntukan & 0,274 & 0,288 & 0,215 & 0,224 \\
\hline 14 & Tingkat rentabilitas usaha & 0,341 & 0,243 & 0,184 & 0,232 \\
\hline
\end{tabular}

\section{Pengolahan Vertikal}

Hasil pengolahan vertikal pada tingkat ketiga menunjukkan bahwa prioritas utama kriteria sukses sebagai tolok ukur keberhasilan LPDB-KUMKM dalam menentukan saluran yang mendukung strategi pembiayaan LPDB-KUMKM yang efektif adalah sukses pemanfaatan $(0,286)$, sukses peningkatan usaha $(0,254)$, sukses pengembalian $(0,243)$ dan sukses penyaluran $(0,217)$ sebagaimana ditunjukkan dalam Gambar 1. Hasil pengolahan vertikal pada tingkat keempat menunjukkan bahwa prioritas utama sub-kriteria sukses penyaluran adalah momentum waktu penyaluran $(0,619)$.

Prioritas utama sub-kriteria sukses pengembalian dalam menentukan saluran yang mendukung strategi pembiayaan LPDB-KUMKM yang efektif adalah kepatuhan mitra dalam pengembalian pokok $(0,241)$. Prioritas utama subkriteria sukses peningkatan usaha dalam menentukan saluran yang mendukung strategi pembiayaan LPDB-KUMKM yang efektif adalah pertumbuhan omset $(0,592)$. Prioritas utama subkriteria sukses pemanfaatan dalam menentukan saluran yang mendukung strategi pembiayaan LPDB-KUMKM yang efektif adalah kesesuaian dengan peruntukan berdasarkan laporan realisasi $(0,633)$.

Sub-kriteria pada sukses peningkatan usaha yang mendapatkan prioritas utama dalam menentukan saluran yang mendukung strategi pembiayaan LPDB-KUMKM efektif adalah pertumbuhan omset dengan bobot 0,592 dan penyerapan tenaga kerja dengan bobot 0,408 . Subkriteria pada sukses pemanfaatan yang mendapatkan prioritas utama dalam menentukan saluran yang mendukung strategi pembiayaan
LPDB-KUMKM efektif adalah kesesuaian dengan peruntukan berdasarkan laporan realisasi dengan bobot 0,633 dan tingkat rentabilitas usaha dengan bobot 0,367 . Hasil sintesis penilaian bobot saluran yang mendukung strategi pembiayaan LPDBKUMKM efektif yang tertinggi adalah koperasi $(0,307)$, UKM $(0,283)$, LKB $(0,207)$ dan LKBB $(0,203)$.

\section{Hasil Analisis Regresi Logistik dan AHP}

Hasil analisis regresi logistik perlu disandingkan dengan hasil analisis AHP untuk mendapatkan hasil yang lebih baik dalam upaya menyusun strategi pembiayaan LPDB-KUMKM efektif. Berdasarkan analisis regresi logistik biner dan AHP yang telah dilakukan terdapat fokus analisis yang saling mendukung antara satu dan lainnya.

Analisis regresi logistik biner menjelaskan tentang bagaimana hubungan antara peubah dependen dan independen yang berdasarkan hipotesis akan memengaruhipeubah dependen (sukses pengembalian) yang merupakan faktorfaktor non-linear yang memengaruhi kolektibilitas dana bergulir LPDB-KUMKM.Hasil analisis AHP memasukkan semua faktor baik linear maupun non-linear, yang ditujukan mengetahui faktor paling dominan terkait dengan empat tolok ukur sukses LPDB-KUMKM, sebagai prioritas saluran mana yang akan dipilih, sekaligus mengetahui bobot dari masing-masing saluran yang akan digunakan, untuk menjawab pencapaian strategi yang paling efektif. Hasil analisis regresi logistik menunjukkan faktor-faktor yang memengaruhi sukses pengembalian berdasarkan nilai nyata adalah pola pembiayaan (X3), plafon pinjaman (X4) dan lama usaha (X5). Analisis AHP untuk 


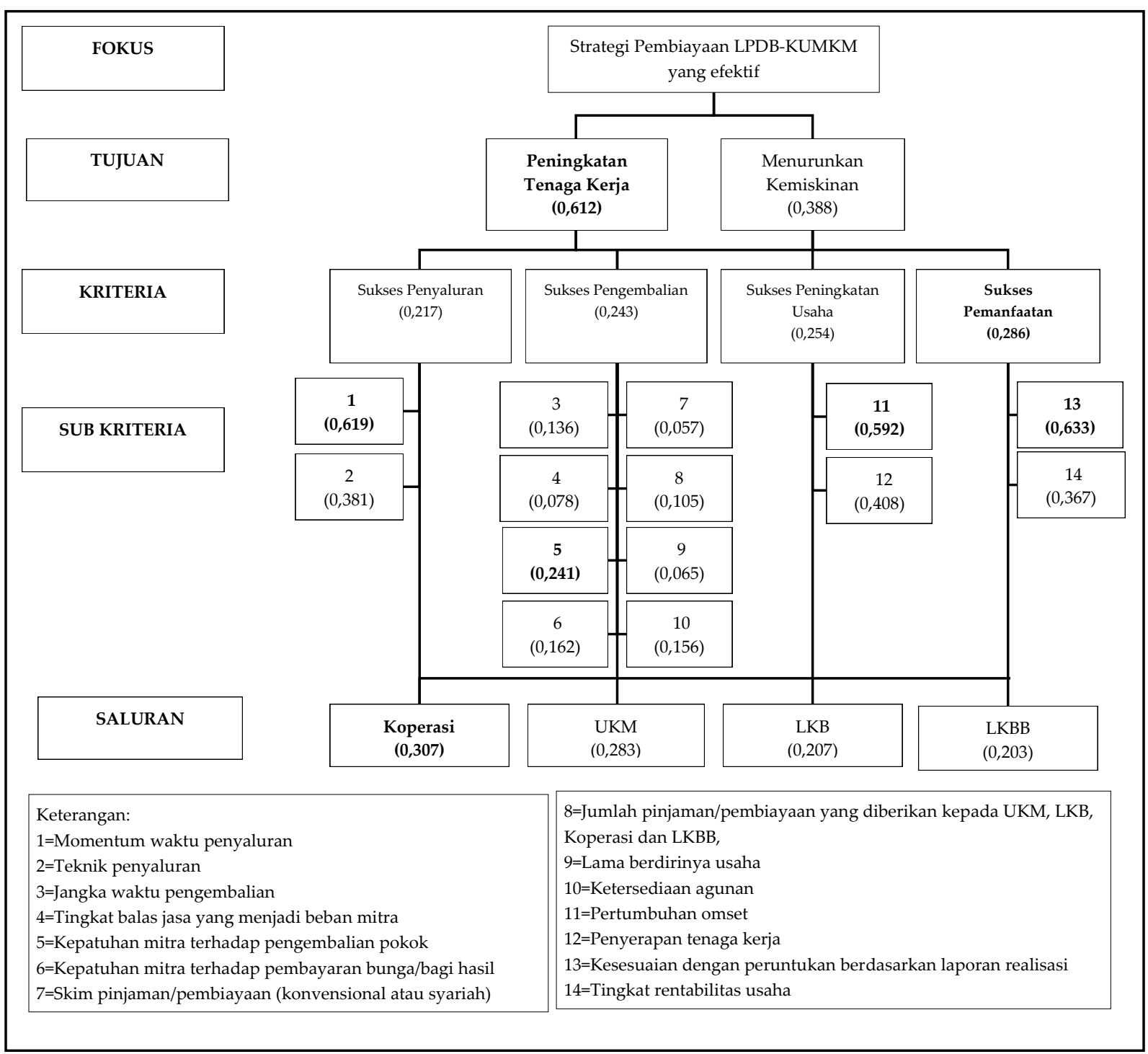

Gambar 1. Struktur dan nilai bobot hirarki berdasarkan analisis AHP

kriteria sukses pengembalian menunjukkan prioritas sub kriteria yang dianggap paling dominan secara berurutan adalah kepatuhan mitra dalam pengembalian pokok, kepatuhan mitra dalam pengembalian bunga, ketersediaan agunan, jangka waktu pinjaman dan plafon pinjaman. Hasil analisis regresi logistik dinilai menyempurnakan hasil analisis AHP, dimana dalam menentukan sukses pengembalian, hasil pengolahan dari penilaian pendapat para pakar dengan menggunakan AHP menyatakan peran faktor pola pembiayaan dan lama usaha masih belum menjadi pertimbangan prioritas.

Hasil analisis regresi logistik menunjukkan saluran pemberian pinjaman atau pembiayaan melalui koperasi cenderung memiliki mutu pinjaman lancar yang lebih rendah dibandingkan dengan UKM. Hal ini berbeda dengan hasil analisis AHP yang menunjukkan urutan prioritas saluran pemberian pinjaman atau pembiayaan adalah koperasi, UKM, LKB dan LKBB. Hal ini dapat dimaknai kemampuan koperasi dalam pengembalian pinjaman UKM relatif lebih baik dibandingkan dengan koperasi, namun koperasi tetap dipilih menjadi prioritas yang perlu dipertimbangkan sesuai analisis AHP karena pemerintah menjadikan koperasi sebagai instrumen pemberdayaan ekonomi masyarakat dengan menjadikan koperasi sebagai lembaga keuangan alternatif bagi pelaku usaha mikro di wilayahnya, sekaligus sebagai lembaga yang dimiliki langsung oleh masyarakat.

Data portofolio pemberian pinjaman atau pembiayaan yang dituangkan dalam Rencana Bisnis dan Anggaran (RBA) LPDB-KUMKM dari tahun 2012 hingga 2016, menunjukkan dari total ketersediaan Dana Bergulir yang akan disalurkan setiap tahun, prioritas pemberian pinjaman atau pembiayaan masih didominasi oleh saluran koperasi yang selanjutnya secara berturut-turut 
disalurkan kepada UKM, LKB dan LKBB. Merujuk pada portofolio pemberian pinjaman atau pembiayaan berdasarkan RBA LPDBKUMKM tahun 2012 hingga 2016 dan hasil analisis regresi logistik serta AHP, maka portofolio pinjaman pada masa mendatang dinilai perlu untuk disesuaikan dengan lebih memerhatikan porsi pemberian pinjaman atau pembiayaan kepada UKM, LKB, dan LKBB sehingga dapat meningkatkan efektivitas penyaluran pinjaman atau pembiayaan.

\section{Strategi Peningkatan Kinerja LPDB-KUMKM}

Mengacu pada hasil analisis kinerja, analisis regresi logistik dan AHP, maka usulan strategi yang dapat dipertimbangkan dalam meningkatkan kinerja LPDB-KUMKM adalah memperhitungkan peningkatan efektivitas penyaluran pinjaman atau pembiayaan, yang meliputi saluran pinjaman atau pembiayaan dan faktor-faktor yang berpengaruh secara nyata terhadap sukses pengembalian. Mempertimbangkan faktor-faktor yang harus menjadi pertimbangan dalam penyusunan strategi penyaluran pinjaman atau pembiayaan dilakukan dengan cara berikut:

1. Memberikan prioritas penyaluran pinjaman atau pembiayaan dana bergulir melalui koperasi dan menyesuaikan portofolio pinjaman dengan lebih meningkatkan porsi pemberian pinjaman atau pembiayaan melalui saluran UKM, LKB dan LKBB.

2. Meningkatkan selektivitas dan ketelitian proses pemberian pinjaman atau pembiayaan kepada koperasi serta merancang sistem monitoring dan evaluasi yang efektif pasca pemberian pinjaman, guna menekan potensi terjadinya risiko meningkatnya pinjaman atau pembiayaan dengan klasifikasi tidak lancar.

3. Melakukan upaya mitigasi risiko yang lebih kuat dalam penyaluran pinjaman atau pembiayaan melalui saluran koperasi, karena koperasi memiliki risiko tingkat klasifikasi pinjaman tidak lancar lebih tinggi dibandingkan pemberian pinjaman atau pembiayaan melalui saluran LKB dan LKBB.

4. Mendorong peningkatan pemberian pembiayaan melalui pola syariah dengan mempertimbangkan data empiris yang menunjukkan pembiayaan dengan pola syariah memiliki kecenderungan lebih lancar daripada pinjaman dengan pola konvensional.

5. Mempertimbangkan pemberian pinjaman atau pembiayaan dengan jangka waktu lama usaha dari calon mitra, utamanya terkait dengan penentuan besaran plafon yang lebih tinggi dalam upaya meningkatkan mutu pinjaman atau pembiayaan dalam kategori lancar.

6. Memperbaiki waktu penyaluran pinjaman atau pembiayaan melalui peningkatan pemahaman dan pengetahuan para pengurus dan pengelola koperasi, sehingga meningkatkan efektivitas proses pemberian pinjaman atau pembiayaan kepada koperasi.

7. Mendorong pemberian pinjaman kepada sektor usaha yang secara bisnis mampu mendorong terbukanya peluang penyerapan banyak tenaga kerja baru dengan harapan peluang bagi tenaga kerja baru tersebut memberikan peluang penghasilan yang lebih baik, sehingga mampu menekan tingkat kemiskinan.

\section{KESIMPULAN}

1. Faktor-faktor yang memengaruhi kinerja dana bergulir LPDB-KUMKM terkait dengan sukses pengembalian yang berkorelasi nyata adalah pola pembiayaan, plafon pinjaman dan lama usaha. Faktor pola pembiayaan menunjukkan bahwa kecenderungan pembiayaan dengan pola syariah untuk sukses dalam pengembalian meningkat 0,326 kali dibandingkan pola konvensional. Faktor plafon pinjaman menunjukkan secara positif memengaruhi kelancaran pengembalian secara mutlak (linear) sebesar satu kali, dimana bila plafon meningkat maka dipastikan akan sukses pengembalian pinjaman atau pembiayaan. Faktor lama usaha menunjukkan semakin tinggi lama usaha, maka kecenderungan untuk sukses dalam pengembalian semakin meningkat secara mutlak (linear) 1,004 kali, yang berarti semakin tinggi lama usaha, maka dipastikan mutu pengembalian pinjaman atau pembiayaan akan semakin baik.

2. Mengacu pada hasil analisis kinerja, regresi logistik dan AHP, maka usulan strategi yang dapat dipertimbangkan dalam meningkatkan kinerja LPDB-KUMKM adalah memperhitungkan peningkatan efektivitas penyaluran pinjaman atau pembiayaan, yang meliputi saluran pinjaman atau pembiayaan dan faktorfaktor yang berpengaruh nyata terhadap sukses pengembalian. 


\section{DAFTAR PUSTAKA}

Asmara, E. 2007. Tingkat Pengembalian Pinjaman Dana Ekonomi Produktif Masyarakat dan Peran Lembaga Keuangan pada Program Pemberdayaan Ekonomi Masyarakat Pesisir di Kabupaten Indramayu. Jurnal Manajemen Agribisnis, Vol. 4 No. 1:p22-31.

Boot, W.A. Arnound, dan Anjan V. Thakor. 1987. Collateral and Borrower Risk. Netherland: University of Tilburg.

Elsiefy, E. 2013. Comparative Analysis of Qatari Islamic Banks Performance Versus Conventional Bank Before, During, and After Financial Crisis. Egypt: Alexandria University.

Ismanto, H dan T. Diman. 2014. Analisis Efektivitas Pemberian Pinjaman Program Pembiayaan UMKM oleh Koperasi. Jurnal Economia, Vol. 10 No.2: p148-164.

Kementerian Koperasi dan UKM. 2014. Perkembangan data Usaha Mikro, Kecil, Menengah (UMKM) dan Usaha Besar (UB) tahun 2012 - 2013. [Internet]. [diunduh 2017 Jan 9]; Tersedia pada: http://www.depkop.go.id/ berita-informasi/data-informasi/dataumkm/.

2011. Rencana Strategis Kementerian Koperasi dan Usaha Kecil Menengah Republik Indonesia Tahun 2010-2014. Jakarta.

Kristiansen, S., B. Furuholt \& F. Wahid. (2003). Internet cafe entrepreneurs: pioneers in information dissemination in Indonesia. The International Journal of Entrepreneurship and Innovation, 4(4): p251-263.
Ladue, E.L. dan A.Z. Gordon. 1984. Variable Interest Rates and The Financial Performance of Dairy Farm Business. USA: Cornell University. LPDB-KUMKM (Lembaga Pengelola Dana Bergulir Koperasi dan Usaha Mikro Kecil dan Menengah). 2015. Laporan Kinerja Tahun 2015. Jakarta.

Lubis, A. dan D. Rachmina. (2011). Faktor-Faktor yang Mempengaruhi Realisasi dan Pengembalian Kredit Usaha Rakyat. Jurnal Forum Agribisnis, Volume 1, No. 2:p112131.

LPDB-KUMKM. 2015. Laporan Kinerja Tahun 2015. Jakarta.

Munizu, M. 2013. Strategi Peningkatan Kinerja dan Peran Usaha Kecil dan Menengah (UKM) Pengolah Produk Berbasis Pangan di Kota Makassar. Jurnal Ubaya. Repository Universitas Hasanudin[Internet]. [diunduh 2016 Nov 7]; Tersedia pada: http://repository.unhas.ac.id/handle/123456789/4299.

Tamba, H., T. Syarif dan M.A. Nakolas. 2013. Kajian Kinerja Dana Bergulir LPDB KUMKM. Jurnal Pengkajian Koperasi dan UKM: Jurnal. [Internet]. [diunduh 2016 Sep 22]; Tersedia pada: http://www.jurnal. smecda.com/index.php/pengkajiankukm/ar ticle/view/89/83. 